\title{
Providing Online Information Services to Small Farm Owners
}

\author{
Valentina Tudor ${ }^{1}$, Alexandru SIPICĂ $\breve{A}^{2}$ \\ ${ }^{1}$ University of Agronomic Science and Veterinary Medicine, \\ valentina_tudor@yahoo.com \\ 2 National Institute for Research and Development in Informatics - ICI Bucharest, \\ alexandru.sipica@ici.ro
}

\begin{abstract}
The ever faster development of information technologies as well as the progress to information society trigger the increased use of IT tools (software and hardware) in the business environment. This article presents the concept of designing a gateway to the continuous information needed by the small agribusinesses. Although agriculture is the economic sector with the least use of information science, the professional success of the agriculture business players and their mere existence on the market is in part due to the use of computers. The concept is based on a survey carried out in the agricultural business environment of Lunguletu village in Romania. In order to test the formulated hypotheses, we used the nonparametric method for the comparison among Chi square groups.
\end{abstract}

Keywords: investments, economic size, system architecture, Chi square, agribusiness, database, SGDB

\section{Introduction}

It is widely recognized that 'the current economic situation and the high level of market uncertainty force companies to continuously adapt to respond to constant changes'. [3]

In a rapidly changing world, the EU wants to become a smart, sustainable and inclusive economy. These three priorities support one another and are able to help the EU and its Member States to achieve a high level of employment, productivity and social cohesion.

The Romanian rural economy, dominated by agriculture, largely remains poorly integrated into the market economy. In today's business environment in agriculture, the welfare of citizens in rural and urban areas as well as the welfare of agricultural producers depends on understanding and using the informationsharing techniques.

The Romanian producer must act in accordance with the current economic reality at world and national level, use technical and economic methods that ensure stability and safe economic efficiency. The producer has to produce what is required on the domestic and international market, to react promptly to consumer's needs.

The current economic and financial crisis, the most severe in the past decades, has seriously affected Europe, whose economy contracted significantly. Official documents mention that in order to record sustainable growth, a programme should be jointly agreed upon taking into account primarily the people and responsibility. Thus the EU 2020 Strategy is designed as a successor to the current Lisbon Strategy, which was the EU reform strategy in the past decade and helped the EU face the recent crisis [15].

The crisis, as official documents state [13], cancelled years of economic and social progress and highlighted structural weaknesses in Europe's economy. Today, Europe's main objective should be to go back on track. In order to ensure a sustainable future, Europe must already look beyond short term priorities. Faced with an aging population and global competition, we have three options: to work more sustainably, to work harder or work smarter. In fact as shown in the European Commission documents, Europe 2020 strategy through the Digital Agenda for Europe aims at drawing a map in order to use the social and economic potential of ICTs to the maximum, especially the Internet, which is a vital support for economic and social activities, whether they relate to business, working, playing, communicating and expressing ourselves freely. [9]

The creation of a comprehensive information society which will ensure the economic and work force development that will further lead to better quality public services and better quality of life; digital information has undoubtedly gained an unprecedented leading role in the development of all domains of activity as well as of each individual. [1]

\subsection{Current situation \& related approach}

Because more and more daily activities are performed online, from applying for a job to 
paying taxes or purchasing tickets, the use of the Internet has become an inherent part of daily life for many Europeans. However, at European level, about $30 \%$ of the population have never used the Internet. They often say that they do not need or that is too expensive. This group is mostly made up of people between 65 and 74 years of age, people with low incomes, unemployed and people with a lower education level. [4]

In many cases, this exclusion is due to lack of skills associated with the use of digital tools and media, which affects not only the ability to learn, create and participate, but also the confidence and discernment in the use of digital media. At the same time, accessibility and practicality are issues for people with disabilities. Bridging the digital gap can help the members of disadvantaged social groups to participate on equal terms in the digital society (including services of direct interest to them such as eLearning, eGovernment, eHealth) and to find a solution to their problems by increasing the chances of getting a job. Thus, the digital skill is one of the eight key competences that are essential for people in a knowledge society [4]. Similarly, this power is essential in everyone's understanding how online security is provided.

\subsection{Aims of this work}

Minimizing the risk in agriculture and providing economic growth including functional relationships upstream and downstream in the agricultural industry are the main strategic objectives at county level. In the EU, the FET Flagship Initiatives mission is to go beyond the conventional boundaries of ICT and venture into uncharted areas, increasingly relying on fresh synergies, cross-pollination and convergence with different scientific disciplines (for instance, biology, chemistry, nanoscience, neuro- and cognitive science, ethology, social science, economics) and with the arts and humanities [18].

The main objective of this study is to create a continuous information system at village level for those who are involved in the agricultural business environment. For a better understanding of the role of information technology in agribusiness activities at village level it was necessary to test the links between various aspects of the business, such as: (marketing, sales, management of agribusiness) and ICT.

\section{Research Model and Hypothesis}

The prerequisites for faster development in information technologies and the transition to the information society trigger the increased use of IT tools (software, hardware) in the business environment. Bill Gates divides the business environment into two categories, stating that: "Today's businesses are of 2 types: online and not at all" [12]. Although agriculture is the domain with the least use of information science, the agriculture business players' success and their mere existence on the market is increasingly due to the use of computers. Agriculture is a specialized activity that involves not only the production, but also parts of other branches, distribution, trade, "agriculture as specialised human activity includes not only the area of production, but also parts of the distribution of agricultural goods and services" [11].

The research model stages are (Figure 1):

The work sample. It was established based on the data provided by the Romanian public authorities. The lack of a cadastre plan led to identifying the work sample based on the application of Romanian Law 1/2000 (The Law to re-establish the property right on agricultural land and forestry required proper to Land Law nr. 18/1991)

Stratification criterion. The size of the Romanian rural space, as well as the rural development specific to the region in which the case study was carried out, required selecting $5 \%$ of the families performing (agricultural or nonagricultural) activities in the selected region;

Establishing the selection methodology. This was done using a software programme to generate random numbers. Thus, random numbers were generated for the $5 \%$ established according to the stratification criterion. The data obtained using the software was imported into an excel spreadsheet, and it was saved using the '.csv' extension;

Research criteria. It was necessary to generate 17 relevant criteria which illustrate the use of information-sharing techniques in agricultural businesses. Thus, the 17 criteria refer to: education, age, profession, holding size, crop structure, household revenues, financial satisfaction, access to information, use of the computer, products' prices, products' advertising, products' marketing, attitude to 


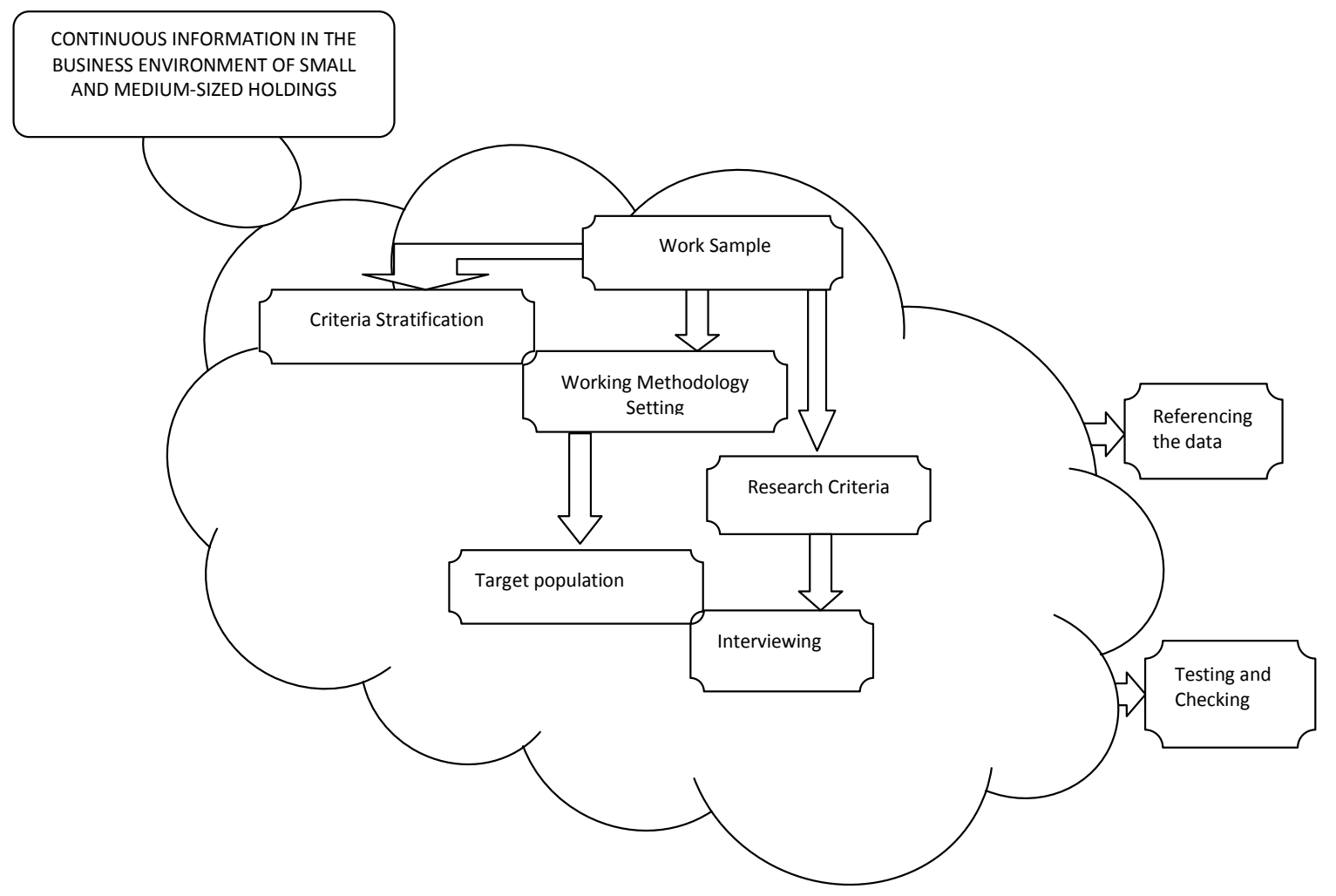

Figure 1. Determining the connection between agribusiness activities and the use of ITCs

innovations, household equipment, investments, projects;

Target population. In establishing the target population, we used the table of randomly generated numbers. At the beginning of this stage we established that each randomly selected number corresponds to a number in the agricultural register. Thus, it was easy to identify the households where we applied the questionnaire. We also established here that for data accuracy purposes, it is necessary that the interviewees belong to one of the following categories: head of the household (family, company), or any other relative that lives in the household and performs agricultural activities, or other types of activities in the household. [9]

The interview. The people were interviewed according to the procedures described above by the participants' filling out questionnaires.

Testing and verifying the hypotheses. For the interview response relevance, it was necessary to formulate hypotheses and to test them using nonparametric techniques for the comparison among groups, the selected method being Chi square. This test implies verifying the association hypothesis among: the responses obtained in a questionnaire connected to a question's multiple choices and verifying a specific set of data that can follow a known statistical distribution. As to the socioeconomic domains, this is applied after the elaboration of contingency tables in which the data are classified according to one, two or several segmentation variables [8]

The main hypotheses that are formulated refer to the connection between the education level, the cultivated areas, the benefits obtained and the use of ITC infrastructures as means of information and business diversification.

Because the expression of the Chi square test is obtained based on observations, it results that it is a statistics and not a parameter, therefore it is also called non-parametric statistical test or allocation-free test, namely a test that does not depend on the form of the initial basic law [6].

According to the methodology, in using the test we start from the following hypotheses:

- $\boldsymbol{H}_{\mathbf{0}}$ there are no significant differences between the actual and expected frequencies, which implies that there is no connection between the analysed variables,

- $\quad \boldsymbol{H}_{\mathbf{1}}$ there are significant differences between the actual and expected frequencies, which means there is a connection between the analysed variables. [5] 


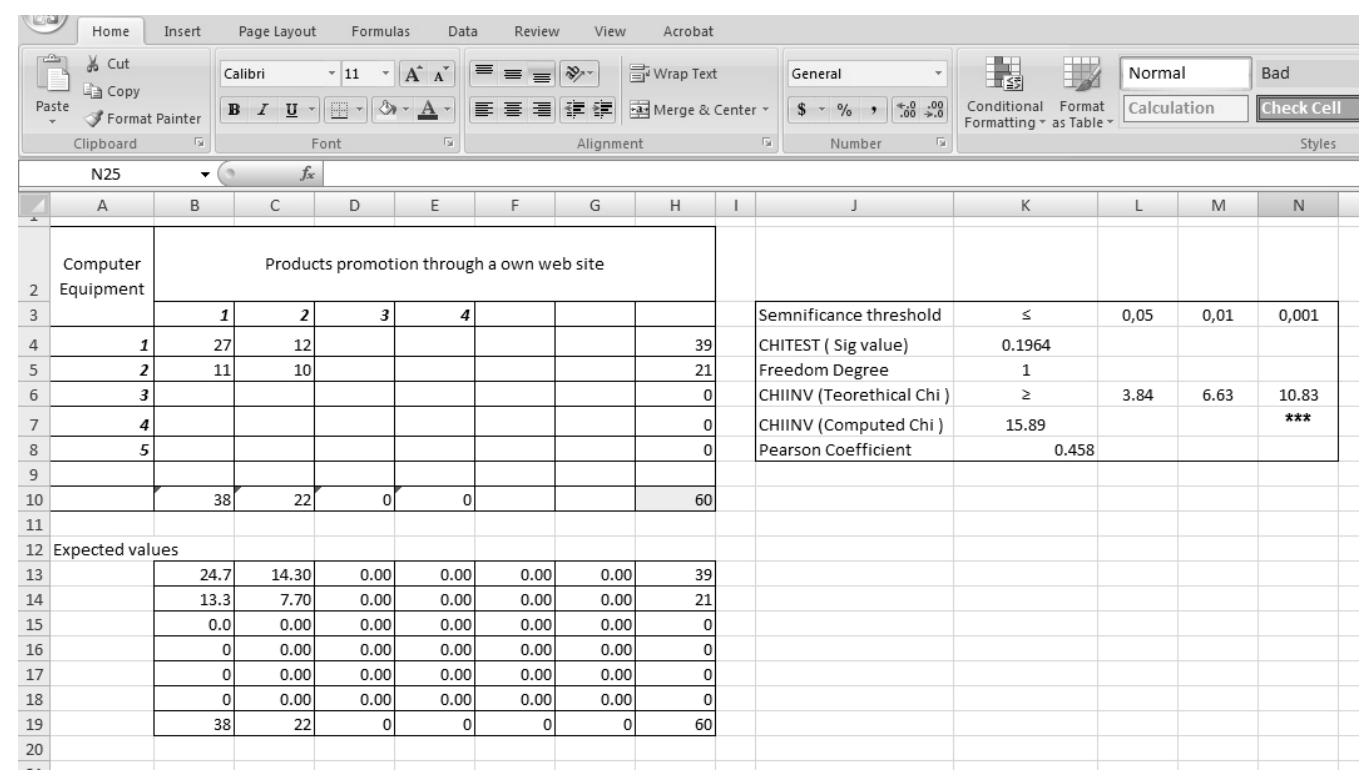

Figure 2. Testing the hypothesis that there is a connection between the educational level of the agricultural holding's members and the opportunity to use e-commerce [9]

CHINV returns the reverse of the single alternative probability of the Chi square allocation. If the probability $=\operatorname{CHIDIST}(\mathrm{x} ; \ldots)$, then CHIINV (probability;...) $=\mathrm{x}$. This function was used in comparing the actual and expected results in order to establish if the hypotheses are valid.

Below we present the hypotheses which turned out to be highly significant after the testing, namely [17]:

- There is a connection between the education level of the agricultural holding's members and the opportunity to use e-commerce (Figure 2);
We notice a very significant connection and infer that all those college educated people also take initiative in using e-commerce services in developing agricultural activities and business. Thus, we believe actions are necessary to show the advantages of using the information technology in the field of electronic services usage.

- There is a connection between the wish to have one's own website to promote products on the Internet and the computer equipment (Figure 3).

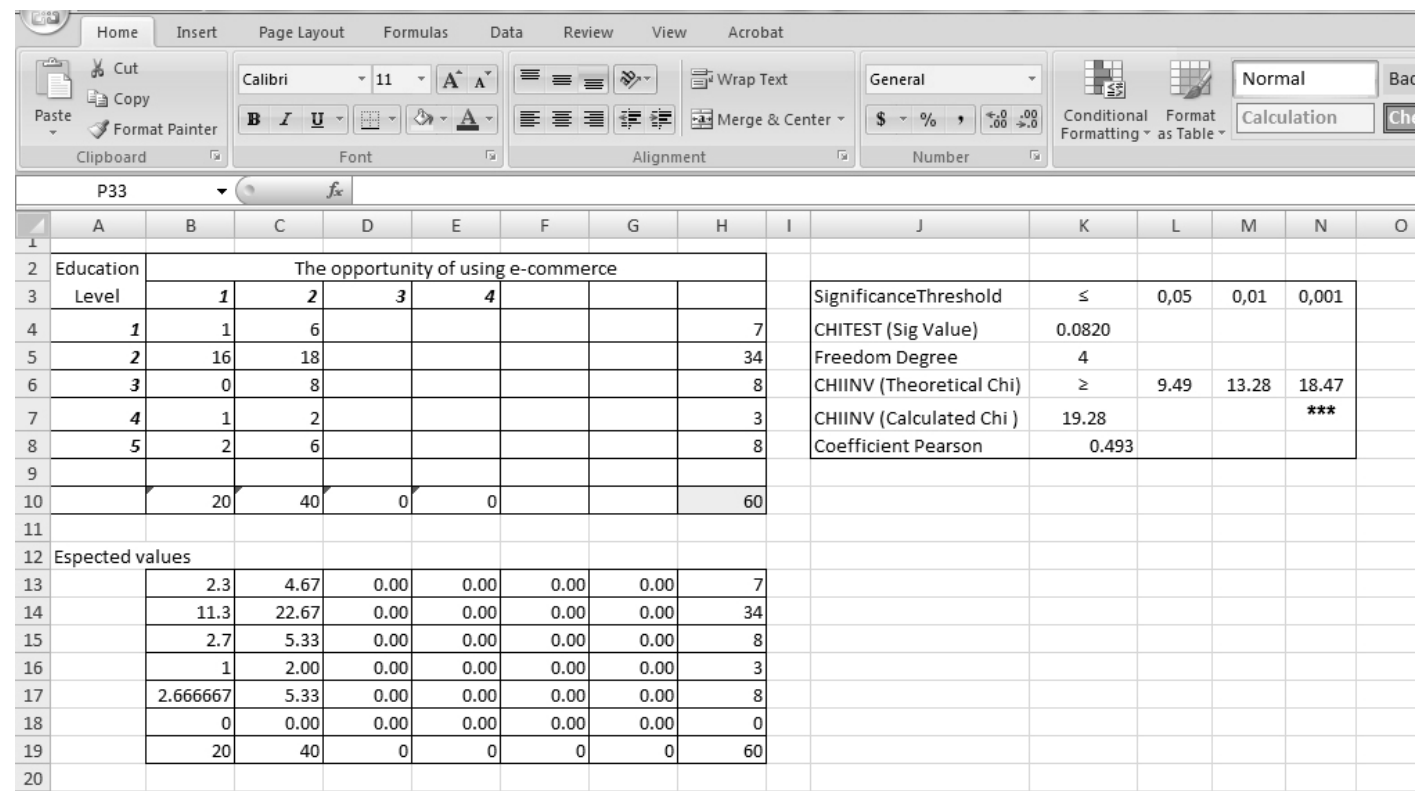

Figure 3. Testing the hypothesis that there is a connection between the wish to have one's own website to promote products on the Internet and the computer equipment [9]. 


\section{Information Service Portal}

The research performed and the case study highlights the main conclusion: the lack of information both in the agricultural process and in the business development and diversification. Thus, it is necessary to create tools in the online environment for the business environment in Romanian agriculture. The priority of this study was to design an information system to cover both the customisation of a homepage for the marketing of agricultural products and the issue of consulting provided to farmers.

The portal, as a concept, provides two types of information, local information, for the local business environment and for national business environment.

The Information structure of the portal suggested for the proposed information service is organized on two levels:

- The first level, informational, contains specific information of particular importance to farmers (agriculture, agritourism, animal husbandry, environment protection, contact)

- The second level, Agribusiness, contains agricultural business information (agricultural consulting, products promotion, subsidies, exchange rates).

From the perspective of a system architecture meant for the interaction between the citizen and the business environment, Banciu D., [2] describes as platform architecture solution, an integrated system of portal type. Thus the portal ensures the integrity of the information from several (structured or non-structured) data sources and presented by means of a web-type interface. Viewing and accessing the data will be differentiated according to the user type interacting with the system.

The lack of information and of a consultant amplifies the degree of agricultural business risk exponentially. The proposed platform has a three -level architecture: Interface, Relational coding and database.

The concept of the portal for the continuous information in agriculture brings a design based on web 2.0 technologies and developed using HTML5, CSS and PHP (Hypertext Processor) for the interface as well as MySQL for databases.
The portal's web interface was created using HTML 5 and CSS which introduces a series of advantages such as [14]:

- It is supported by all new browsers;

- The published website is loaded faster in HTML5, which is an important factor for SEO;

- The website is also visible on smart phones (iPhone, Android phones, Windows phones);

- compared to standard HTML, the HTML5 format website may contain animated text and pictures with special effects with the possibility of installing plug-ins

- the website is also optimised for regular desktops computers and for tablets (e.g. iPad).

The advantages of using database management system are mainly the following:

- data redundancy control;

- data coherence;

- more information from the same amount of data;

- data sharing;

- increased security;

- improvement in data accessibility and response capacity.

The information provided at the first level allows people involved in agricultural activities to have access to all the necessary information through one access point.

Regarding information at the second level, it is organised in two modules:

- Consulting for investments in agricultural business;

- Advertising and promotion on the Internet;

It is vital that at the beginning of an agricultural business, or even in diversifying the activities, we should know what funding is needed, how much we can obtain from the funding. Thus, the information means provide the possibility to briefly present each development measure, as well as the possibility to calculate online the number of existing ESU and the necessary ones for the eligibility of the proposed activities.

Assessing the technical and economic potential of crops and animal species is perhaps the most important use because the calculation methodology creates the possibility of assessing the production potential of the area and the holding using the production per acre 


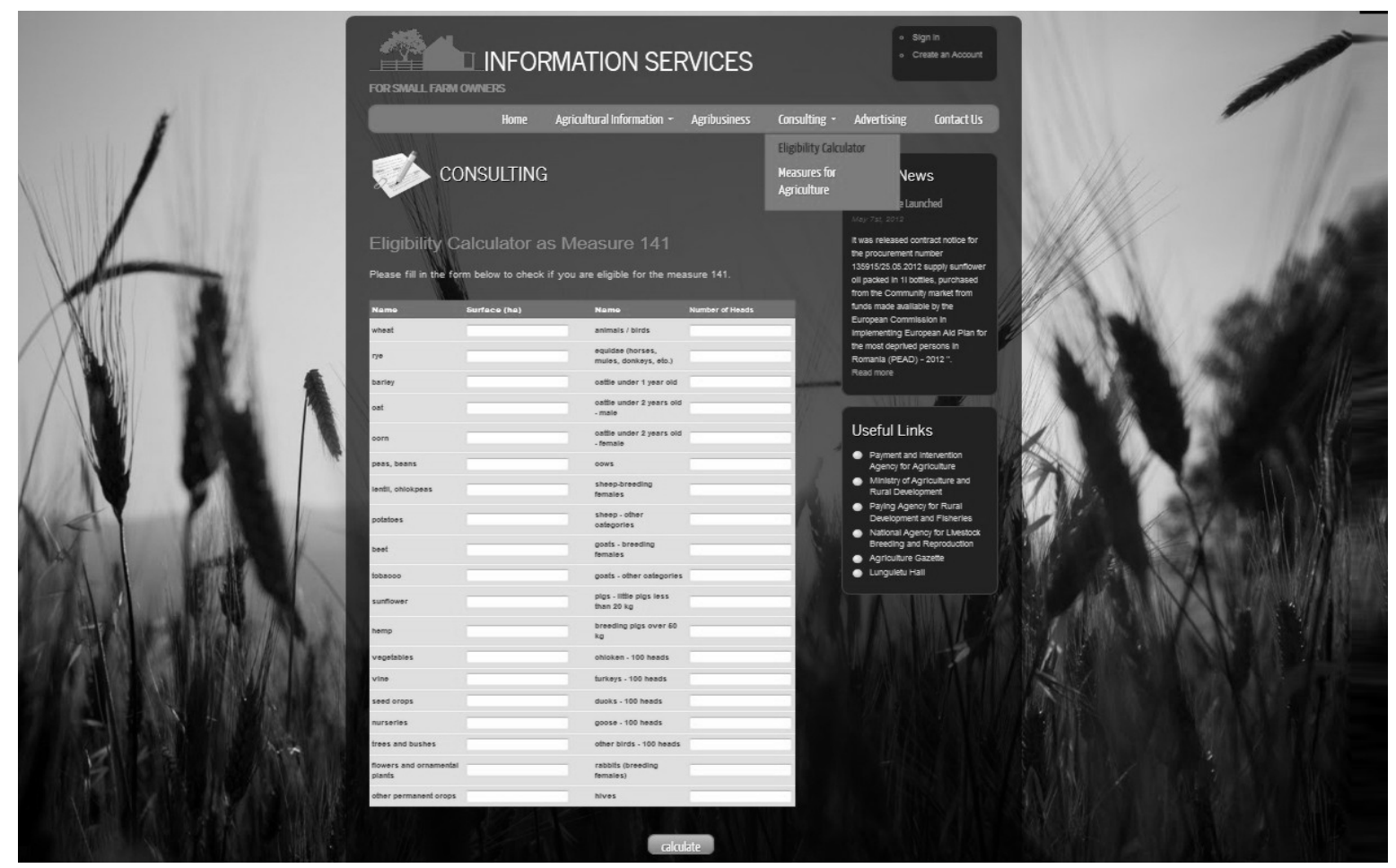

Figure 4. Calculating Eligibility Online for Agricultural Business

or animal, and technical-economic assessment of production technologies by the size of the production factors, the final prices and MBS size characterizing a given holding. [10]

The first module provides mostly an overview of the measures for investment in agricultural businesses. Secondly, it gives the possibility to calculate the eligibility by establishing the number of European Size Unit, a measurement of economic size used in farming ESU required because of funding, as shown in Figure 4.

The data are collected from the real world based on observations and measurements. The information is the result of interpreting data by a particular individual and gives them the ability to make decisions. In this context, an important role is played by databases as the primary means of storing and retrieving data and implicitly providing information.[9]

The problem of calculating the ESU leads to the need to create a database with coefficients for each crop. The database will be created and permanently updated with data provided by the Ministry of Agriculture and Rural Development [11]. Thus, databases are created and managed using MySQL. Using PHP scripts in the user interface provides compatibility with almost any SGDB, which facilitates importing information from other databases or tables.

Another major problem in agriculture is products advertising and marketing. Given that the study and research show that farmers are interested in using the Internet as a source of advertising, the advertising module allows each farmer to configure on his own the structure of the information about the products they want to promote.

The administration manner allows the user, through a login module, to have the right to set their own page with information specific to the activity (name, surname, contact information, product, price, quality, quantity, product image upload).

The User Mode allows those interested in purchasing products, or those who are interested in developing business to find the ideal partner.

Also, the user can search the database of the information portal for information about the quality of the products offered by producers, the price of the products offered by producers or the producers' contact information (phone, address, e-mail) 


\section{Discussion \& Conclusions}

1. The hypotheses formulated and tested after completion of the case study reveal the existence of a strong connection between the education level and the business information and diversification opportunity.

2. The fact that the calculated CHINV (15.89) is higher than the theoretical CHINV, allows us to conclude that there is a strong connection between the wish to have one's own website and to promote products on the Internet.

3. The portal concept is based on the one hand on supporting those who want to diversify or to set up business in agriculture, providing the user with a way to verify eligibility and, on the other hand, offers the possibility to create one's own page, for those who want to promote their products and services online;

4. By introducing HTML5 and CSS components in the portal design, there are substantial benefits such as: compatibility with all new browsers, the published website loads faster in HTML5, which is an important factor for SEO; site visibility on smart phones as well (e.g. iPhone, Android phones, Windows phones). Compared to standard HTML, the HTML5 format website may contain animated text and pictures with special effects, making it possible to install some plug-ins; the website is also optimized for regular desktop computers and tablets (eg . iPad).

\section{Limitation and Future Research}

The online information service was tested locally, the database being available only for the established working sample in the study. The need for local consulting centers, the lack of funds and specialised personnel, result in a low level of access to EU development funds.

Creating an online media consulting center to calculate parameters such as: return on investment, internal profitability rate and estimated profit is a priority for future research in the field.

\section{REFERENCES}

1. BANCIU, D., e-Romania - A Citizens' Gateway towards Public Information, Studies in Informatics and Control, Vol. 18, No. 3, 2009, pp 205-210;

2. BANCIU, D., e-Tax by InfoCHIOŞC, Editura Tehnică, Bucureşti, 2002

3. CUENCA, L., A. BOZA, A. ORTIZ, Architecting Business and IS/IT Strategic Alignment for Extended Enterprises, Studies in Informatics and Control, Vol. 20, No. 1, 2011, pp 7-18;

4. DOROS I., Databases, Publishing House of Cybernetics Bucharest, 2010;

5. DUMITRU E., Economic Statistic, U.S.A.M.V. Bucharest, 2005;

6. IOSIFESCU, M., ş. a., Small Statistics Encyclopaedia, Scientific publishing and Encyclopaedic, Bucharest, 1985

7. LUPASC, A. Databases Applied in Economics,

http://www.scribd.com/doc/56790887/15/A vantajele-\%C5\%9Fi-dezavantajele-SGBDurilor;

8. MIHĂIȚĂ, N. V., Strong Statistical Relationships, Hidden, False and Illusory, http://www.biblioteca-digitala.ase.ro/biblio teca/carte2.asp?id=388\&idb=, accessed 04.07.2012

9. SIPICĂ A., Research on the Business Environment in a Farm - Case Study, Doctoral Thesis, Unpublished, 2012

10. TUDOR, V., Farm Management, Ceres Publishing House, Bucharest, 2008,

11. ZAHIU, L., Agricultural Management, Economic Publishing House, 1999.

12. *** Digital Agenda for Europe general framework of action, accessed 1 august 2012, www.mcsi.ro/Minister/AgendaDigitala/Agenda_Digitala

13. *** Help and support center, http://www.cabanova.com/help/ro/Knowle dgebase/Article/View/1128/204/care-suntavantajele-tehnologiei-html5

14. *** Commission of the European Communities Consulting Commission Working Document on the future Strategy 
15. „UE 2020”, 2009, http://ec.europa.eu/dgs/secretariat_general/ eu2020/docs/com_2009_647_ro.pdf

16. *** Ministry of Agriculture and Rural Development, MADR, 2012, Calculation of UDE Coefficients and Typology, http://www.madr.ro/pages/page.php?sub=0 $2604 \&$ self $=26000$

17. *** Microsoft Office, Chitest, http://office.microsoft.com/ro-ro/excelhelp/chitest-HP005209012.aspx
18.

http://eurlex.europa.eu/LexUriServ/LexUri Serv.do?uri=COM:2010:0245:FIN:RO:HT ML

19. *** Science beyond fiction, Future and Emerging Technologies, 2011, ftp://ftp.cordis.europa.eu/pub/news/researc h-eu/docs/focus9_en.pdf 